\title{
When Nuance Is Not an Option: Facing Prognostication Inaccuracy at Perceived End-of-Life
}

\author{
Lavi Oud
}

\section{To the Editor}

Discussions about the prognosis trajectories associated with critical illness are part of daily interactions between ICU physicians and patients' surrogates. While risk of death is a common part of these discussions, clinicians commonly express such risks in broad qualitative terms [1]. This nuanced approach reflects prognostication uncertainty for individual critically patients, contrasting the marked improvements in populationlevel prognostication performance of contemporary severityof-illness scoring systems [2]. Despite surrogates' interest in prognostic information provided by physicians, the former are well aware about the limited accuracy of this information [3]. Importantly, while surrogates generally clamor for certainties in outcome expectations, the imprecision in pronouncements on death prognostication for individual patients helps sustain a much needed hope during critical illness [4].

However, the aforementioned nuanced approach may no longer apply when clinicians strongly believe, based on accumulating data, that hospital death is bound to occur, despite ongoing life-support interventions.

In order to take the next step of withdrawal of life-support in the aforementioned situation, surrogates, who often find such decisions markedly burdensome, even when it is clear that patients would consider continuation of life-support unacceptable, must have complete trust in physician's prognostication validity. The later prerequisite is paramount in order for surrogates to abandon hope for patient's survival, as withdrawal of life-support under these circumstances is generally considered a step with irreversible, permanent consequences. Under these circumstances, the communication by physicians can no longer be nuanced. Rather, they are expected to convey in the most compassionate manner the equivalent message of "this is it" about unavoidable death to allow surrogates to come to terms about the expected outcome.

Against this backdrop of need for trust and clarity, recent studies have quantified the substantial level of outcome inaccuracy when clinicians indicate that a given critically ill will die. Thus, Meadows and colleagues reported that even

Manuscript submitted December 22, 2017, accepted January 4, 2018

Division of Pulmonary and Critical Care Medicine, Department of Internal Medicine, Texas Tech University Health Sciences Center at the Permian Basin, 701 W. 5th Street, Odessa, TX 79763, USA. Email: lavi.oud@ttuhsc.edu

doi: https://doi.org/10.14740/jocmr3336w among those patients judged uniformly to die by all involved ICU clinicians, $15 \%$ survive hospitalization [5]. In a more recent study by Detsky et al, the investigators found that even among patients about whom their physicians provided confident predictions of hospital deaths, $50 \%$ of those predicted to die survived hospitalization [6]. Perhaps more sobering is the recent report by Lobo and colleagues, showing that among ICU patients in North America with a decision to withhold/withdraw life-sustaining treatment, 44\% survived hospitalization [7]. Given prognostication inaccuracy, some of the deaths in the later study may represent a self-fulfilling prophecy [6].

Although our understanding of surrogates' expectations during critical illness has markedly improved [4], we need to gain better insight into the magnitude of prognostication uncertainty, if any, that surrogates are willing to tolerate and yet proceed with withdrawal of life-support interventions when faced with expected hospital death of patients.

We cannot expect, for the foreseeable future, to gain the capability to offer prognostic certainty on hospital death to surrogates of the critically ill. However, armed with the accumulating data added by recent studies, ICU clinicians should look for means to ease surrogates' decision-making burden when facing the realities of our limitations in individual-patient prognostication.

\section{Conflict of Interest}

The author declares that there is no conflict of interest regarding the publication of this paper.

\section{Grant Support}

None.

\section{References}

1. Hall JB. Making recommendations for limiting care in the ICU based on sound prognosis. JAMA. 2017;317(21):2170-2171.

2. Bouch DC, Thompson JP. Severity scoring systems in the critically ill. BJA CEPD. 2008;8(5):181-185.

3. Zier LS, Burack JH, Micco G, Chipman AK, Frank JA, Luce JM, White DB. Doubt and belief in physicians' 
ability to prognosticate during critical illness: the perspective of surrogate decision makers. Crit Care Med. 2008;36(8):2341-2347.

4. Evans LR, Boyd EA, Malvar G, Apatira L, Luce JM, Lo B, White DB. Surrogate decision-makers' perspectives on discussing prognosis in the face of uncertainty. Am J Respir Crit Care Med. 2009;179(1):48-53.

5. Meadow W, Pohlman A, Frain L, Ren Y, Kress JP, Teuteberg W, Hall J. Power and limitations of daily prognostications of death in the medical intensive care unit. Crit
Care Med. 2011;39(3):474-479.

6. Detsky ME, Harhay MO, Bayard DF, Delman AM, Buehler AE, Kent SA, Ciuffetelli IV, et al. Discriminative accuracy of physician and nurse predictions for survival and functional outcomes 6 months after an ICU admission. JAMA. 2017;317(21):2187-2195.

7. Lobo SM, De Simoni FHB, Jakob SM, Estella A, Vadi S, Bluethgen A, Martin-Loeches I, et al. Decision-making on withholding or withdrawing life support in the ICU: a worldwide perspective. Chest. 2017;152(2):321-329. 